\title{
Learning Styles, Performance, And Attitudes Towards Technology: Focus On Business Students
}

\author{
Joyce Njoroge, (Email: Joyce.Njoroge@drake.edu), Drake University \\ Jimmy Senteza, (Email: Jimmy.Senteza@drake.edu), Drake University \\ Inchul Suh, (Email: Isuh@drake.edu), Drake University
}

\section{INTRODUCTION}

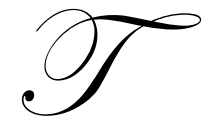

here has been a significant move towards the use of technology in university academic instruction over the last 20-plus years in the United States. Colleges have jumped at the opportunity to 'wire' their campuses, assigning vast amounts of financial resources to provide state-of-the-art instructional technology. The need to be at the forefront of the technology curve is evident in the emphasis colleges place on campus information technology in their prospectuses. Admissions offices seem to view their university's technological capabilities as a critical criterion for attracting, admitting, and eventually retaining good students. Moreover, most institutions now offer various forms of online instruction and academic degrees can be earned entirely through online instruction. Nevertheless, several questions have not been addressed. What are the students' attitudes towards technology and how do they relate to their performance? Research has revealed that students differ in their learning styles. Do students with different learning styles perceive the use technology for instruction similarly? Have preferred learning styles changed over the past 20-plus years as technology has evolved? What are the typical learning styles of today's undergraduate students? Does the student's major, gender, learning style, and/or attitude toward the use of technology for instruction affect his/her performance? Generally, it is hard to claim that the academic community fully understands how today's typical undergraduate student learns, and what their attitudes towards the use of technology in classroom instruction is. This study attempts to address these points and to provide a more current assessment of business students' learning styles and how technology relates to those styles with reference to academic performance.

This paper is organized as follows. Section II provides related literature review. We describe our data collection process in Section III. In Section IV, we report our findings on students' learning styles. Relationship between students' attitudes toward technology and their academic performance is explored in Section V. Section VI contains conclusions and suggestions for future research.

\section{LITERATURE REVIEW}

Studies on learning styles indicate that there are differences among students enrolled in various business majors and in different colleges. Most of the published studies on learning styles of business students were carried out more than a decade ago, using the Kolb Learning Style Inventory (LSI). ${ }^{1}$ The LSI instrument identifies ways in which individuals learn and how they resolve learning issues on a day-to-day basis. Respondents are asked to rank 12 sentences based on their learning preferences. The rankings are then added up to generate scores for four different learning modes for each respondent. The four different learning modes are: Concrete Experience (CE), Reflective Observation (RO), Abstract Conceptualization (AC), and Active Experimentation (AE). The LSI produces two combined scores, AC-CE and AE-RO, which are plotted on a quadrant to establish four different learning styles: Diverging, Assimilating, Converging, and Accommodating.

According to Kolb (1999), divergers develop ideas by using their imaginative abilities in looking at concrete situations from many different points of view. Assimilators focus more on abstract ideas and concepts and less on

\footnotetext{
${ }^{1}$ Baldwin and Reckers (1984), Biberman and Buchanan (1986) and Holley and Jenkins (1993)
} 
people. Their strength lies in the development of theoretical models and in their ability to put information into concise and logical form. Convergers excel at developing practical applications of ideas and theories. Accommodators learn by doing things and carrying out new ideas and experiments. They prefer 'hands-on' experience rather than logical experience. Although most learners have one preferred style, an effective learner is one who can apply different styles to different learning situations.

Biberman and Buchanan (1986) found that there are differences in preferred learning styles of students in various majors. They found that accounting majors, like science majors, tended to be convergers while economics/finance majors were likely to be accommodators. They also found that management and marketing majors tended to be divergers. Using the same instrument, Loo (2002) divided business students into "hard" and "soft" majors. Hard majors are defined as majors that emphasize quantitative materials or technical materials (finance, accounting and information system). On the other hand, soft majors are defined as those majors emphasizing people (management, marketing, human resource management etc). He found that hard majors tended to be assimilators while soft majors leaned more towards accommodator learning style. He also found that gender did not play a role in the distribution of learning styles, and that students in business schools tended to be assimilators. Filbeck and Smith (1996) found that, for Corporate Finance majors, success as measured by performance in exams is correlated with learning styles. Learning style has also been found to be significantly related to performance on various examination formats. In their study of accounting students, Holley and Jenkins (1993) examined four examination formats; multiple-choice theory, multiple-choice quantitative, open-ended theory, and open-ended quantitative. They found that there was a significant relationship between learning styles and performance on each examination format except for the multiple-choice quantitative format. Their study found that students with the AC learning mode performed better on open-ended theory questions compared to students with the CE learning mode. Further, AE learning mode was positively associated with performance on open-ended quantitative questions as compared to RO learning mode. None of these studies, however, addressed the relationship between learning style and the use of instructional technology.

For the context of this paper, technology is defined as an electronic tool to communicate or process information. The use of technology in learning situations has increased tremendously in the last two decades. The growing demand for higher education, diversity of student population, and development of information technology have all led to increased use of technology in learning environments (Saunders and Klemming, 2003). As such, pedagogical technology ranges from using PowerPoint in classrooms to having textbooks on CD ROMs, using search engines in classrooms and offering web based courses. Numerous studies have examined the value of technology in the classroom. Rainbow and Sadler-Smith (2003) studied 300 business and management undergraduates and found that irrespective of their age, gender or educational background, they had a positive outlook towards computerassisted learning. Sabry and Baldwin (2003) found that in the learning process, students value interaction with information (such as the web or virtual lecture) more than they value interaction with tutors or with other students. Research on attitudes and perceptions toward technology has found differences by gender. Brunner and Bennett (1998) found that boys were more positive and excited about technology than girls. They suggest usage of classroom technology should reflect the interests of both girls and boys. From the educators' point of view, research suggests that technology usage in terms of media delivery systems, audio/visual aids, computer training and multimedia can be used to enhance different learning styles (Wynd and Bozman (1996)). The question of students' attitude towards technology and how it relates to their learning styles remains unanswered.

\section{METHODS AND ANALYSES}

The primary data for this study were obtained from administering two survey instruments to a sample of undergraduate students at Drake University in Des Moines, Iowa, during the fall semester 2004. The first instrument used was the standard Kolb Learning Style Inventory (LSI). The LSI, as discussed earlier, is a widely used learning style instrument employed in several prior studies. The second instrument was a questionnaire designed to assess and understand student attitudes toward technology in a university classroom (see Appendix I). The questionnaire consisted of 37 items several of which had to do with perception of and satisfaction with the instructional use of technology. A five-point Likert scale was used for each question to gauge attitudes/perception. Demographic information about each individual respondent including race, age, gender, foreign/non-foreign student's status, home 
country, major, and number of online courses previously taken was also collected. The two questionnaires enabled us to examine the association between how individuals learn (learning styles) and their attitudes toward technology. Data on the cumulative grade point average (GPA) were also collected and matched up with student responses to assess relationship between learning styles and performance.

The sample consisted of all freshmen registered for the introductory Accounting class, all sophomores registered for Statistics I course, all juniors registered for the Corporate Finance course and seniors who were taking the business capstone course. All four courses are required for business majors. Since the surveys were conducted during regular class time, the participation rate is close to $100 \%$.

A total of 318 undergraduate students consisting of 71 freshmen, 47 sophomores, 86 juniors, 100 seniors and 14 'others' (non-traditional part-time) students were surveyed. Overall, 166 students have a single major while 44 students were open business or undecided. One hundred and eight students were double or joint majors ${ }^{2}$.

\section{LEARNING STYLES}

Table 1 shows the breakdown of the sample by year of study and identified learning style. Almost 70 percent of the students surveyed were either convergers (40.57 percent) or assimilators (29.56 percent). A detailed breakdown of the responses by major and by type of major ("hard" and "soft" following Loo (2002)) is provided in Table II. Double majors clearly make up the bulk of students with a converging learning style, followed by the undecided students, marketing and management majors. Almost one third of the assimilators were either undecided majors or double majors and an analogous distribution occurs for accomodators as well. Hard majors were likely to be convergers $(45.6 \%)$ or assimilators $(32 \%)$ whereas soft majors were most commonly convergers $(36.8 \%)$ but likely to be accommodators or assimilators (at $25.6 \%$ each).

In order to assess the change in learning styles over the last twenty years, we compare average LSI scores of our respondents with those in Biberman and Buchanan (1982) - B\&B hereafter. Mean AC-CE and AE-RO scores for each major are calculated and reported in Table III. Then, based on these scores, each major is plotted on a learning style grid as in Chart 1 which details the findings in both the B\&B and our study. The gridlines used for their study are reprinted to provide comparison between the two studies. ${ }^{3}$

The findings in this study differ from those of B\&B in two significant ways. First and most importantly, there seems to have been a drift in learning styles of business students over the last twenty plus years. A close look at Chart 1 shows a seemingly southwesterly shift in the plotting of the average LSI scores of comparable business students on the Kolb chart. Secondly, B\&B found that students majoring in accounting were likely to be convergers, those majoring in marketing and management likely to be divergers, and those majoring in economics and finance likely to be accommodators. Unlike the B\&B results, however, this study finds marketing and management majors along with accounting, actuarial science, economics, finance and international business majors score on average in the converger quadrant. In fact, management-marketing joint majors and actuarial science-finance joint majors were found to be convergers. Only information systems, general business and undeclared business, majors plus accounting-finance joint majors scored on average in the assimilator quadrant. Overall, the findings suggest that over time there have probably been changes in the way students in the different majors learn and the changes seem to have been directionally consistent with the southwesterly shift.

There are several ways to look at the two results described above. First, the availability and use of varied forms of technology at home, in schools, places of work and other facets of life have increased magnificently over the last twenty plus years. Unlike students who took the B\&B survey in the early eighties, our respondents are students who grew up with technology in all its different forms at home and in school. They used PCs at home and at school (i.e. K through 12). They use technology in their cars, at the grocery store, in the movie theatres and rentals, at the amusement park check in, at the restaurant and several other places. The difference in familiarity with technology

\footnotetext{
${ }^{2}$ Joint majors are students whose total degree hours are taken in two emphasis areas rather than one. Unlike double majors who earn two separate degrees, joint majors earn a single degree in the two areas of emphasis.

${ }^{3}$ The scale use in this study is consistent with the one used in Hay Resources Direct - manual distributed with the LSI surveys.
} 
between this generation of students and their age peers over twenty years ago is like night and day. Because of the way technology generally functions, today's students' learning styles and the drift toward converging could be the result of the technology. It is likely that they have grown up to appreciate and desire to apply themselves through mental and other exercises, they like the benefits of finding solutions to questions quickly and efficiently and they would rather deal with technical tasks and problems than with interpersonal relationships. These constitute typical traits of learners with converging learning style who, according to Kolb (1985), excel at developing practical applications of ideas and theories and may be enhanced, admittedly, by the use of technology. The second questionnaire we use aids the study in attempting to characterize the observed change which is being attributed to attitudes towards technology.

\section{DOES TECHNOLOGY MATTER?}

To investigate the respondents' attitudes toward technology, a technology score (called TECHSCORE) is computed from responses to questions on the second questionnaire and compared to identified learning styles. TECHSCORE is computed by aggregating the responses to questions 6-10 and 14-25 of the questionnaire in Appendix I. ${ }^{4}$ TECHSCORE in this study has a mean of 59.5 and ranges from a low of 30 and a high of 79 . A high TECHSCORE represents a more positive attitude towards technology while a low TECHSCORE represents a less positive attitude towards technology.

Chart 2 Panels A and B show the relationship between TECHSCORE and both learning styles and GPA controlling for type of major (hard or soft). The top chart seems to suggest that students in the hard majors might have a slightly more positive attitude toward technology compared to students in the soft majors. This is especially true if the student has a converging or an assimilating learning style. Overall, students with the assimilating learning style seem to have the least appreciation for the use of technology in the classroom, as their TECHSCORE is always lower on average. Although Panel B of chart 2 visually shows the relationship between attitudes towards technology and a student's grade point average (GPA), it does not indicate whether the relationship is statistically significant. It does however suggest that students with higher GPAs do not have as high a regard for the use of technology for instruction as those with lower GPAs.

Both the panels in Chart 2 are limited in the analytical basis in that they do not specify the statistical significance of the relationship observed. They however provide some framework for examining the association between the students' attitudes towards technology and their class performance. We performed t-tests to validate the observed differences in attitudes toward technology across learning styles, gender, and GPA score for the sample as well as for hard and soft majors. Results of the test of equality of the mean TECHSCORE between the different learning styles are reported on Table IV-A. The only learning styles that have significantly different TECHSCOREs are the converging and assimilating learning styles. This is consistent with results on Chart 2-A. On average the TECHSCORE for students with an assimilating learning style are significantly lower than those of students with a converging learning style. This holds true when hard majors are separated out (Table IV-B) but does not hold for soft majors (Table IV-C). In effect, we confirm that, on average, attitudes toward technology tend to be relatively same across all learning styles except between convergers and assimilators who are also hard majors.

We also look at the equality of the mean GPAs across different learning styles. Results appear in Table V. Convergers have a significantly different and higher average GPAs than students exhibiting the other learning styles with assimilators having the next higher GPAs (Table V-A). There is no significant difference in GPAs between accommodators and divergers. Further examination show that, hard majors, especially convergers, had the higher GPAs (Table V-B). For soft majors, there does not seem to be any difference in GPA for students exhibiting different learning styles (Table V-C).

Examining by gender, we find no difference in the attitudes towards technology for male and female students (Table VI). On the other hand, female students on average have significantly higher GPAs than male students (Table VII).

\footnotetext{
${ }^{4}$ Questions 14-18 are scored in a reverse order from the rest of the questions. The scores to these questions are similarly reverse aggregated.
} 
Results of the differences in means and those reported on Chart 2 raise important theoretical questions that deserve further analysis. For example, it can be hypothesized that there is an association between individual learning styles and attitudes toward technology. Secondly, given the mixed assessment from Chart 2-B, the hypothetical question becomes "Do individual attitudes toward technology impact academic performance?" In essence, we examine the theoretical question of whether one's attitude toward the use of technology in class instruction is related to overall academic performance.

Academic performance can be measured in several ways but the use of student GPA is perceivably the most logical way to capture it. In analyzing the impact of the students' technology attitudes, learning styles and gender were used as moderating or controlling variables. The following regression was run to examine the possible association between students' attitudes toward technology and their performance:

$\mathrm{GPA}_{\mathrm{i}}=\mathrm{a}+\mathrm{b}_{1}$ TECHSCORE $_{\mathrm{i}}+\mathrm{b}_{2}$ Gender $_{\mathrm{i}}+\mathrm{b}_{3} \mathrm{LS}_{\mathrm{i}}+\mathrm{b}_{4} \mathrm{LS}_{\mathrm{i}}+\mathrm{b}_{5} \mathrm{LS}_{\mathrm{i}}+\square_{\mathrm{i}}$

where,

TECHSCORE $_{\mathrm{i}}=$ the composite score from the technology survey for student $\mathrm{i}$.

$\mathrm{GPA}_{\mathrm{i}}=$ the cumulative grade point average for students $i$.

Gender $_{i}=$ the gender dummy variable equaling one if the student is male, and zero otherwise.

$\mathrm{LSX}_{\mathrm{i}}$, where $\mathrm{X}=2$ or $\mathrm{X}=3$ or $\mathrm{X}=4$ which represent dummy variables equaling 1 if student $\mathrm{i}$ has a learning style of a diverger, converger or assimilator respectively, zero otherwise.

The results of model (1) appear in Table VIII for all respondents as well as for hard and soft majors separately. The regression results not surprisingly correspond with the findings revealed by chart $2 \mathrm{~B}$. For sample students, attitudes towards technology are not related to performance. However, gender, and learning style did correlate with performance. Female students in our sample had a higher GPA on average than male students as captured in the regression. Also, for those with a hard major, a converger or assimilator learning style improved one's GPA significantly. Indeed, the better GPAs were those of female respondents taking hard majors who were convergers, followed closely by hard major females who were assimilators.

Indeed if we asked college students today about their perception of the use of technology for instructional use, it may be like posing the question of how people feel about accomplishing routine travel by car as opposed to traveling on a horse carriage. Technology and its use are embedded in their overall social, economic, political and cultural structures such that their attitudes and perceptions regarding technology may not be significantly different from one another.

\section{CONCLUSIONS AND SUGGESTIONS FOR FUTURE RESEARCH}

Technology use among today's generation of students is embedded in their lifestyle to such an extent that it has become a cultural norm. The attitudes towards technology for the respondents in this study did not seem to influence their performance as measured by their GPA. Similarly, the obvious shift in learning styles towards more converging and assimilating learning styles is not explained by attitudes towards technology in this study. While this study clearly reports a shift in learning styles over the last twenty-plus years, the cause of that shift needs to be explored further. This study acts as a starting point for other areas of interest in the study of the relationship between technology, learning styles and performance.

One interesting expansion to this study would be to incorporate age in the analysis. While most of the respondents in this study were college-age traditional students, it would be interesting to study the relationship between learning styles and attitudes towards technology for non-traditional students. Mature older students' attitudes towards technology may be different from that of young traditional students in that they may not have grown up with as much technology as the younger students have, and that may influence their learning styles. 
The instructional value of technology remains to be studied further. It is likely that the actual use of instructional technology, and not attitudes towards technology, would impact students' academic performance. As a way to explore this, the study could be extended to a higher education setting with limited technological usage. Also, such a setting would probably help answer the question of whether technology influences learning styles. Finally, it would also be interesting to expand the study to explore the role technological proficiency plays in influencing learning styles and academic performance.

\section{REFERENCES}

1. Baldwin, B. A. \& Reckers, P. M. (1984). Exploring the role of learning style research in accounting education policy. Journal of Accounting Education, Fall, pp. 63-76.

2. Biberman, G. A. \& Buchanan, J. (1986). Learning style and study skills differences across business and other academic majors. Journal of Education for Business, 61, pp. 303-307.

3. Brunner, C. \& Bennet, D., (1998). Technology perceptions by gender. Education Digest, 63, pp. 56-58.

4. Filbeck, G. \& Smith, L. L. (1996). Learning styles, teaching strategies, and predictors of success. Financial Practice and Education, spring/Summer, pp.74-85.

5. Filbeck, G. \& Webb, S. (2000). Executive MBA education: Using learning styles for successful teaching strategies. Financial Practice and Education, spring/Summer, pp.205-215.

6. Hay Resources.

7. Holley, J. H. \& Jenkins, E. K. (1993). The relationship between student learning style and performance on various test question formats. Journal of Education for Business, 68, pp.301-308.

8. Kolb, D. (1999). The Kolb Learning Style Inventory, Version 3. Hay Resources Direct.

9. Loo, R. (2002). The distribution of learning styles and types for hard and soft business majors. Educational Psychology, 22, pp. 349-360.

10. Rainbow, S. W. \& Sadler-Smith, E. (2003). Attitudes to computer-assisted learning amongst business and management students. British Journal of Education Technology, 34, pp. 615-624.

11. Sabry, K. \& Baldwin, L. (2003). Web-based learning instruction and learning styles. British Journal of Education Technology, 34, pp. 443-454.

12. Saunders, G. \& Klemming F. (2003). Integrating technology into a traditional learning environment. Active Learning in Higher Education, 4, pp. 74-86.

13. Wynd, W. R. \& Bozman, C. S. (1996). Student learning style: A segmentation strategy for higher education. Journal of Education for Business, March/April, pp.232-235.

Table I: Student Learning Style By Year

\begin{tabular}{|c|c|c|c|c|c|}
\hline Yr & All & Accommodating & Diverging & Converging & Assimilating \\
\hline FR & 71 & 12 & 8 & 25 & 26 \\
\hline SO & 47 & 7 & 2 & 21 & 17 \\
\hline $\mathrm{JR}$ & 86 & 18 & 10 & 38 & 20 \\
\hline SR & 100 & 22 & 13 & 39 & 26 \\
\hline N/A & 14 & 1 & 2 & 6 & 5 \\
\hline \multirow{2}{*}{ Overall } & 318 & 60 & 35 & 129 & 94 \\
\hline & $100.00 \%$ & $18.87 \%$ & $11.01 \%$ & $40.57 \%$ & $29.56 \%$ \\
\hline
\end{tabular}


Table II: Student Learning Style By Major

\begin{tabular}{|c|c|c|c|c|c|}
\hline Major & All & Accommodating & Diverging & Converging & Assimilating \\
\hline Accounting & 22 & 4 & 1 & 9 & 8 \\
\hline Actuarial Science & 16 & 1 & 3 & 9 & 3 \\
\hline Economics & 3 & 0 & 0 & 2 & 1 \\
\hline Finance & 23 & 4 & 2 & 9 & 8 \\
\hline General Business & 25 & 8 & 4 & 7 & 6 \\
\hline International Business & 16 & 5 & 2 & 3 & 6 \\
\hline Information Systems & 10 & 2 & 2 & 3 & 3 \\
\hline Management & 25 & 6 & 2 & 11 & 6 \\
\hline Marketing & 26 & 7 & 3 & 11 & 5 \\
\hline Undecided & 44 & 8 & 6 & 13 & 17 \\
\hline Accounting/Finance Joint Major & 14 & 3 & 0 & 6 & 5 \\
\hline $\begin{array}{l}\text { Actuarial Science/Finance Joint } \\
\text { Major }\end{array}$ & 17 & 2 & 0 & 10 & 5 \\
\hline Other Joint Majors & 6 & 0 & 1 & 3 & 2 \\
\hline $\begin{array}{c}\text { Management/Marketing Double } \\
\text { Major }\end{array}$ & 20 & 4 & 2 & 10 & 4 \\
\hline Other Double Majors & 51 & 6 & 7 & 23 & 15 \\
\hline \multirow{2}{*}{ Overall } & 318 & 60 & 35 & 129 & 94 \\
\hline & $100 \%$ & $18.87 \%$ & $11.01 \%$ & $40.57 \%$ & $29.56 \%$ \\
\hline \multirow{2}{*}{ Hard Majors ${ }^{1,2}$} & 124 & 18 & 10 & 57 & 39 \\
\hline & $100 \%$ & $14.52 \%$ & $8.06 \%$ & $45.97 \%$ & $31.45 \%$ \\
\hline \multirow{2}{*}{ Soft Majors ${ }^{1,2}$} & 125 & 32 & 15 & 46 & 32 \\
\hline & $100 \%$ & $25.60 \%$ & $12.00 \%$ & $36.80 \%$ & $25.60 \%$ \\
\hline
\end{tabular}

1. Following Loo (2002), hard majors include Accounting, Actuarial Science, Economics, Finance, Information Systems and related joint majors such as Accounting/Finance, Actuarial Science/Finance, Accounting/Actuarial Science and Accounting/Information Systems. Soft majors include General Business, International Business, Management and Marketing.

2. Students in both hard and soft majors are excluded. 
Table III: AC-CE and AE-RO Composite Scores of Kolb's Learning Style Inventory ${ }^{1}$

\begin{tabular}{|c|c|c|c|c|c|}
\hline \multirow[b]{2}{*}{ Major } & \multirow[b]{2}{*}{ All } & \multicolumn{2}{|c|}{$\mathrm{AC}-\mathrm{CE}$} & \multicolumn{2}{|c|}{ AE-RO } \\
\hline & & Mean & Std. Dev. & Mean & Std. Dev. \\
\hline Accounting & 22 & 12.18 & 9.80 & 6.27 & 9.60 \\
\hline Actuarial Science & 16 & 13.31 & 7.93 & 9.69 & 8.43 \\
\hline Economics & 3 & 13.00 & 9.17 & 7.67 & 5.77 \\
\hline Finance & 23 & 10.61 & 9.59 & 6.48 & 7.29 \\
\hline General Business & 25 & 7.60 & 11.09 & 4.88 & 9.09 \\
\hline International Business & 16 & 5.44 & 13.20 & 6.88 & 11.40 \\
\hline Information Systems & 10 & 6.30 & 16.39 & 3.70 & 10.66 \\
\hline Management & 25 & 7.88 & 11.08 & 7.64 & 11.36 \\
\hline Marketing & 26 & 5.69 & 7.71 & 7.77 & 9.79 \\
\hline Undecided & 44 & 10.23 & 12.41 & 4.00 & 10.02 \\
\hline Accounting/Finance Joint Major & 14 & 12.14 & 8.72 & 5.00 & 11.27 \\
\hline $\begin{array}{l}\text { Actuarial Science/Finance Joint } \\
\text { Major }\end{array}$ & 17 & 16.76 & 11.55 & 8.88 & 9.03 \\
\hline Other Joint Majors & 6 & 10.50 & 9.85 & 4.83 & 12.42 \\
\hline $\begin{array}{c}\text { Management/Marketing Double } \\
\text { Major }\end{array}$ & 20 & 10.10 & 12.10 & 9.10 & 12.53 \\
\hline Other Double Majors & 51 & 11.71 & 10.73 & 7.51 & 9.49 \\
\hline Overall & 318 & 9.86 & 11.09 & 6.71 & 9.91 \\
\hline Hard Majors $^{2,3}$ & 124 & 12.51 & 10.61 & 6.98 & 9.13 \\
\hline Soft Majors $^{2,3}$ & 125 & 7.56 & 10.63 & 7.02 & 10.47 \\
\hline
\end{tabular}

1. CE, RO, AC and AE: Scores from the Kolb Learning Style Inventory. (CE: Concrete experience, RO: Reflective observation, AC: Active conceptualization, AE: Active experimentation)

2. Following Loo (2002), hard majors include Accounting, Actuarial Science, Economics, Finance, Information Systems and related joint majors such as Accounting/Finance, Actuarial Science/Finance, Accounting/Actuarial Science and Accounting/Information Systems. Soft majors include General Business, International Business, Management and Marketing.

3. Students in both hard and soft majors are excluded. 
Chart 1. All Majors - Average Scores (Comparison with the previous study)

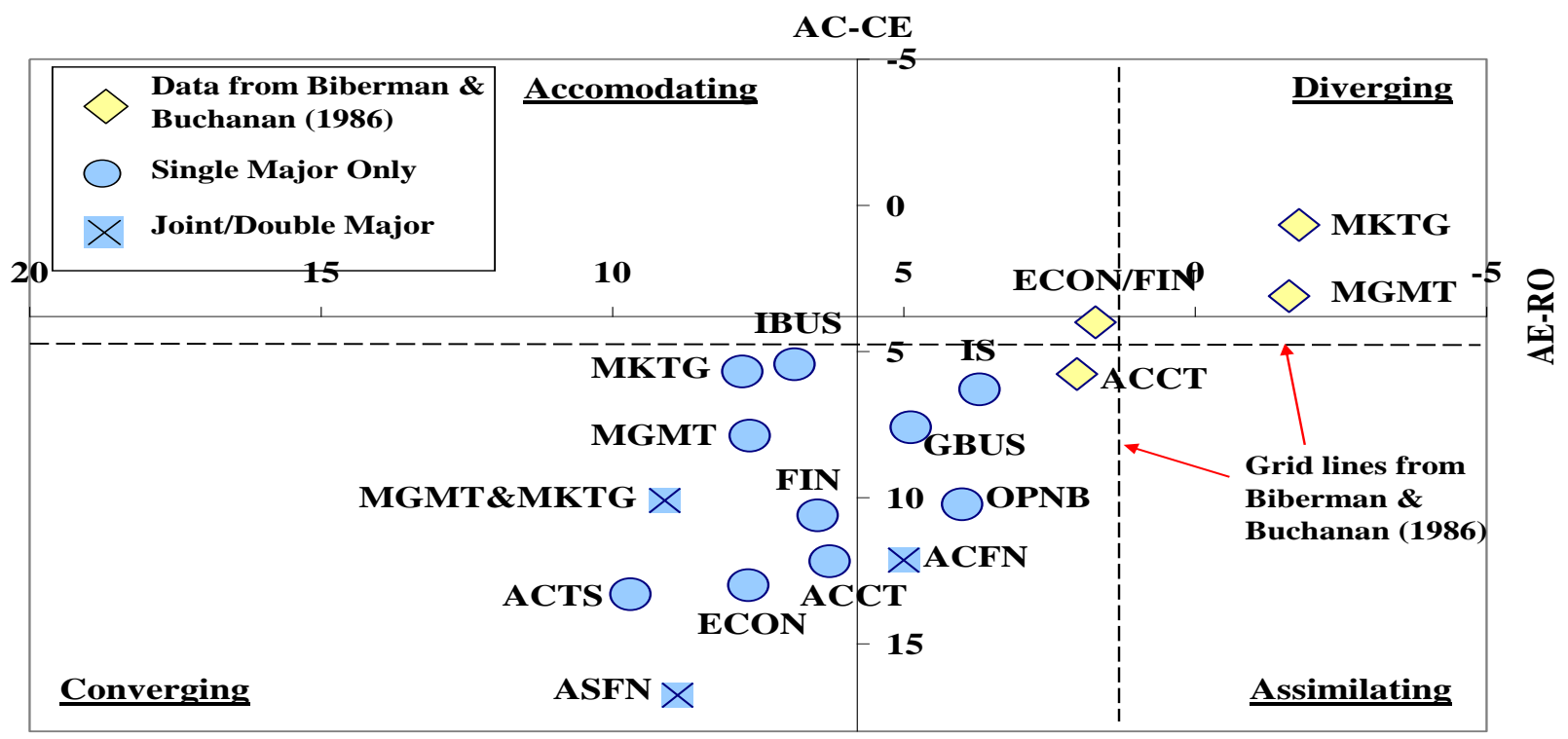

ACCT: Accounting ACTS: Actuarial Science ECON: Economics

FIN: Finance

GBUS: General Business

IBUS: International Business
IS: Information Systems MGMT: Management MKTG: Marketing

ASFN: Actuarial Science/Finance joint major MGMT\&MKTG: Management/Marketing double major

Chart 2-A. Average Techscore by Learning Style

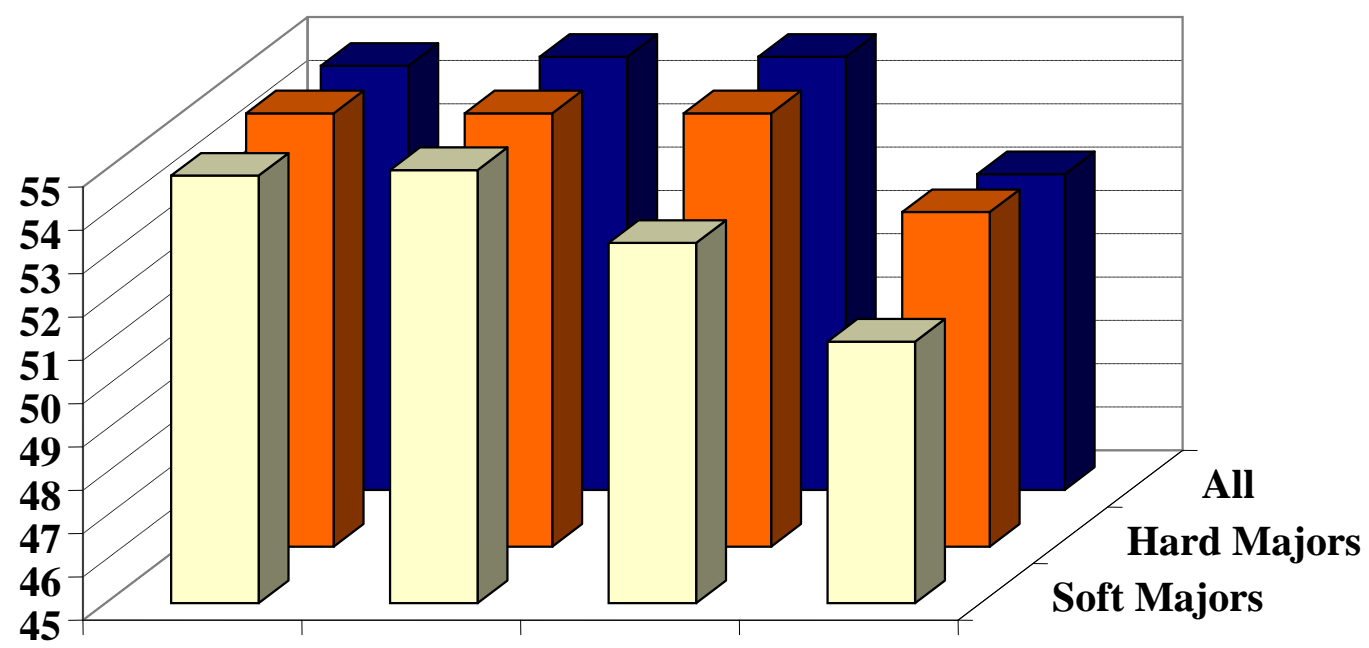

Accommodating Diverging ConvergingAssimilating 
Chart 2-B. Average Techscore by GPA

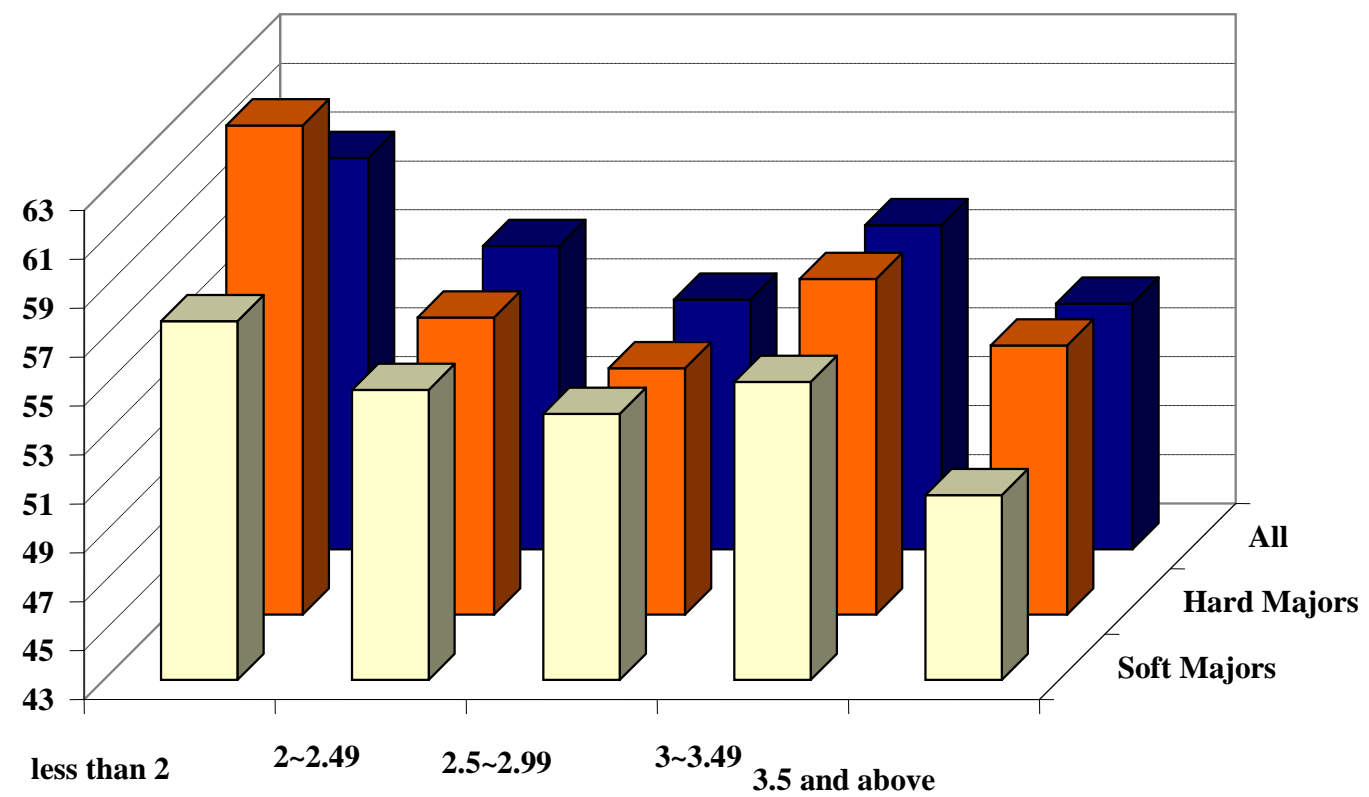

GPA

Table IV: Test for Differences in Mean TECHSCOREs by Learning Style ${ }^{1}$

A. All Majors

\begin{tabular}{|c|c|c|c|c|}
\hline \multirow{2}{*}{ Learning Style } & \multirow{2}{*}{$\begin{array}{c}\text { Mean } \\
\text { TECHSCOREs }\end{array}$} & \multicolumn{3}{|c|}{ Difference in Mean TECHSCOREs } \\
\hline & & Diverging & Converging & Assimilating \\
\hline Accommodating & 54.789 & $\begin{array}{l}-0.630 \\
(-0.28)\end{array}$ & $\begin{array}{l}-0.740 \\
(-0.52)\end{array}$ & $\begin{array}{l}2.460 \\
(1.52)\end{array}$ \\
\hline Diverging & 55.419 & - & $\begin{array}{l}-0.110 \\
(-0.06)\end{array}$ & $\begin{array}{l}3.090 \\
(1.51)\end{array}$ \\
\hline Converging & 55.529 & & - & $\begin{array}{c}3.200 \\
(2.54)^{* *}\end{array}$ \\
\hline Assimilating & 52.329 & & & - \\
\hline
\end{tabular}

B. Hard Majors ${ }^{2,3}$

\begin{tabular}{|c|c|c|c|c|}
\hline \multirow{2}{*}{ Learning Style } & \multirow{2}{*}{$\begin{array}{c}\text { Mean } \\
\text { TECHSCOREs } \\
\end{array}$} & \multicolumn{3}{|c|}{ Difference in Mean TECHSCOREs } \\
\hline & & Diverging & Converging & Assimilating \\
\hline Accommodating & 55.294 & $\begin{array}{l}-1.106 \\
(-0.26) \\
\end{array}$ & $\begin{array}{l}-1.404 \\
(-0.60) \\
\end{array}$ & $\begin{array}{l}2.466 \\
(1.01) \\
\end{array}$ \\
\hline Diverging & 56.400 & - & $\begin{array}{l}-0.298 \\
(-0.09)\end{array}$ & $\begin{array}{l}3.571 \\
(1.04)\end{array}$ \\
\hline Converging & 56.698 & & - & $\begin{array}{c}3.870 \\
(2.14)^{* *} \\
\end{array}$ \\
\hline Assimilating & 52.829 & & & - \\
\hline
\end{tabular}


C. Soft Majors ${ }^{2,3}$

\begin{tabular}{|c|c|c|c|c|}
\hline \multirow{2}{*}{ Learning Style } & \multirow{2}{*}{$\begin{array}{c}\text { Mean } \\
\text { TECHSCORES }\end{array}$} & \multicolumn{3}{|c|}{ Difference in Mean TECHSCOREs } \\
\hline & & Diverging & Converging & Assimilating \\
\hline Accommodating & 54.871 & $\begin{array}{l}-1.283 \\
(-0.37)\end{array}$ & $\begin{array}{l}1.553 \\
(0.67)\end{array}$ & $\begin{array}{l}3.834 \\
(1.37)\end{array}$ \\
\hline Diverging & 56.154 & - & $\begin{array}{l}2.836 \\
(0.99)\end{array}$ & $\begin{array}{l}5.117 \\
(1.55)\end{array}$ \\
\hline Converging & 53.318 & & - & $\begin{array}{l}2.281 \\
(0.99)\end{array}$ \\
\hline Assimilating & 51.037 & & & - \\
\hline
\end{tabular}

1. TECHSCORE: Composite score from the technology survey. Equal variances assumed. t-stats are in parenthesis. (*Significant at $10 \%$ level. **Significant at $5 \%$ level. ***Significant at $1 \%$ level.)

2. Following Loo (2002), hard majors include Accounting, Actuarial Science, Economics, Finance, Information Systems and related joint majors such as Accounting/Finance, Actuarial Science/Finance, Accounting/Actuarial Science and Accounting/Information Systems. Soft majors include General Business, International Business, Management and Marketing.

3. Students in both hard and soft majors are excluded.

Table V: Test for Differences in Mean GPAs by Learning Style ${ }^{1}$

\begin{tabular}{|c|c|c|c|c|}
\hline \multicolumn{2}{|c|}{ A. All Majors } \\
\cline { 3 - 5 } & \multirow{2}{*}{ Mean GPA } & Diverging & \multicolumn{2}{c|}{ Difference in Mean GPAs } \\
\hline Accomming Style & 3.0462 & $\begin{array}{c}0.078 \\
(0.65)\end{array}$ & $\begin{array}{c}-0.288 \\
(-3.37)^{* * *}\end{array}$ & $\begin{array}{c}-0.156 \\
(-1.72)^{*}\end{array}$ \\
\hline Diverging & 2.9686 & - & $\begin{array}{c}-0.365 \\
(-3.51)^{* * *}\end{array}$ & $\begin{array}{c}-0.234 \\
(-2.14)^{* *}\end{array}$ \\
\hline Converging & 3.3338 & & - & $\begin{array}{c}0.132 \\
(1.76)^{*}\end{array}$ \\
\hline Assimilating & 3.2023 & & & - \\
\hline
\end{tabular}

B. Hard Majors ${ }^{2,3}$

\begin{tabular}{|c|c|c|c|c|}
\hline \multirow{2}{*}{ Learning Style } & \multirow{2}{*}{ Mean GPA } & \multicolumn{3}{|c|}{ Difference in Mean GPAs } \\
\hline & & Diverging & Converging & Assimilating \\
\hline Accommodating & 3.1294 & $\begin{array}{l}0.061 \\
(0.28) \\
\end{array}$ & $\begin{array}{c}-0.315 \\
(-2.50)^{* *} \\
\end{array}$ & $\begin{array}{l}-0.196 \\
(-1.42) \\
\end{array}$ \\
\hline Diverging & 3.0686 & - & $\begin{array}{c}-0.375 \\
(-2.11)^{* *} \\
\end{array}$ & $\begin{array}{l}-0.257 \\
(-1.29) \\
\end{array}$ \\
\hline Converging & 3.4439 & & - & $\begin{array}{r}0.119 \\
(1.16)\end{array}$ \\
\hline Assimilating & 3.3251 & & & - \\
\hline
\end{tabular}


C. Soft Majors ${ }^{2,3}$

\begin{tabular}{|c|c|c|c|c|}
\hline \multirow{2}{*}{ Learning Style } & \multirow{2}{*}{ Mean GPA } & \multicolumn{3}{|c|}{ Difference in Mean GPAs } \\
\hline & & Diverging & Converging & Assimilating \\
\hline Accommodating & 3.0462 & $\begin{array}{l}0.147 \\
(0.86)\end{array}$ & $\begin{array}{l}-0.132 \\
(-0.99)\end{array}$ & $\begin{array}{l}-0.100 \\
(-0.72)\end{array}$ \\
\hline Diverging & 2.9686 & - & $\begin{array}{c}-0.279 \\
(-1.69)^{*} \\
\end{array}$ & $\begin{array}{l}-0.248 \\
(-1.51) \\
\end{array}$ \\
\hline Converging & 3.3338 & & - & $\begin{array}{l}0.032 \\
(0.24) \\
\end{array}$ \\
\hline Assimilating & 3.2023 & & & - \\
\hline
\end{tabular}

1. Equal variances assumed. t-stats are in parenthesis. (*Significant at $10 \%$ level. **Significant at $5 \%$ level. $* * *$ Significant at $1 \%$ level.)

2. Following Loo (2002), hard majors include Accounting, Actuarial Science, Economics, Finance, Information Systems and related joint majors such as Accounting/Finance, Actuarial Science/Finance, Accounting/Actuarial Science and Accounting/Information Systems. Soft majors include General Business, International Business, Management and Marketing.

3. Students in both hard and soft majors are excluded.

Table VI: Test for Differences in Mean TECHSCOREs by Gender ${ }^{1}$

\begin{tabular}{|c|c|c|c|}
\hline & \multicolumn{2}{|c|}{ Mean TECHSCOREs } & \multirow{2}{*}{ Differences in Mean TECHSCOREs } \\
\hline & Female & Male & \\
\hline All Majors & 54.444 & 54.596 & $\begin{array}{l}-0.153 \\
(-0.14)\end{array}$ \\
\hline Hard Majors $^{2,3}$ & 56.000 & 54.907 & $\begin{array}{c}1.093 \\
(0.62) \\
\end{array}$ \\
\hline Soft Majors ${ }^{2,3}$ & 54.190 & 52.922 & $\begin{array}{l}1.269 \\
(0.68)\end{array}$ \\
\hline
\end{tabular}

1. TECHSCORE: Composite score from the technology survey. Equal variances assumed. $\mathrm{t}$-stats are in parenthesis. (*Significant at $10 \%$ level. **Significant at $5 \%$ level. ***Significant at $1 \%$ level.)

2. Following Loo (2002), hard majors include Accounting, Actuarial Science, Economics, Finance, Information Systems and related joint majors such as Accounting/Finance, Actuarial Science/Finance, Accounting/Actuarial Science and Accounting/Information Systems. Soft majors include General Business, International Business, Management and Marketing.

3. Students in both hard and soft majors are excluded.

Table VII: Test for Differences in Mean GPAs by Gender ${ }^{1}$

\begin{tabular}{|c|c|c|c|}
\hline \multirow{2}{*}{} & \multicolumn{2}{|c|}{ Mean GPAs } & \multirow{2}{*}{ Differences in Mean GPAs } \\
\cline { 2 - 4 } & Female & Male & $\begin{array}{c}0.1692 \\
(2.65)^{* * *}\end{array}$ \\
\hline All Majors & 3.2946 & 3.1254 & $\begin{array}{c}0.2357 \\
(2.47)^{* *}\end{array}$ \\
\hline Hard Majors & 3.4861 & 3.2504 & $\begin{array}{c}0.3824 \\
(4.01)^{* * * *}\end{array}$ \\
\hline Soft Majors & 3.2185 & 2.8362 & \\
\hline
\end{tabular}

1. Equal variances assumed. t-stats are in parenthesis. (*Significant at $10 \%$ level. **Significant at $5 \%$ level. ***Significant at $1 \%$ level.)

2. Following Loo (2002), hard majors include Accounting, Actuarial Science, Economics, Finance, Information Systems and related joint majors such as Accounting/Finance, Actuarial Science/Finance, Accounting/Actuarial Science and Accounting/Information Systems. Soft majors include General Business, International Business, Management and Marketing.

3. Students in both hard and soft majors are excluded. 
Table VIII: Learning Styles and Academic Performance: Regression Results ${ }^{1,2}$

\begin{tabular}{|c|c|c|c|c|c|c|}
\hline & \multicolumn{2}{|c|}{ All } & \multicolumn{2}{|c|}{ Hard Majors ${ }^{3}$} & \multicolumn{2}{|c|}{ Soft Majors $^{3}$} \\
\hline Intercept & 3.389 & $(16.536) * * *$ & 3.625 & $(11.548) * * *$ & 3.606 & $(11.762) * * *$ \\
\hline TECHSCORE & -0.004 & $(-1.301)$ & -0.007 & $(-1.347)$ & -0.008 & $(-1.510)$ \\
\hline Gender & -0.176 & $(-2.742)^{* * * *}$ & -0.234 & $(-2.379)^{* *}$ & -0.404 & $(-4.008) * * *$ \\
\hline LS2 & -0.049 & $(-0.423)$ & 0.014 & $(0.072)$ & -0.149 & $(-0.870)$ \\
\hline LS3 & 0.302 & $(3.472) * * *$ & 0.350 & $(2.525)^{* *}$ & 0.147 & $(1.169)$ \\
\hline LS4 & 0.169 & $(1.801)^{*}$ & 0.256 & $(1.739)^{*}$ & 0.122 & $(0.842)$ \\
\hline Adj. $R^{2}$ & \multicolumn{2}{|c|}{.072} & \multicolumn{2}{|c|}{.085} & \multicolumn{2}{|c|}{.133} \\
\hline No. of Obs. & \multicolumn{2}{|c|}{257} & \multicolumn{2}{|c|}{101} & \multicolumn{2}{|c|}{105} \\
\hline
\end{tabular}

1. $\mathrm{GPA}_{\mathrm{i}}=\mathrm{a}_{\mathrm{i}}+\mathrm{b}_{1}$ TECHSCORE $+\mathrm{b}_{2}$ Gender $+\mathrm{b}_{3} \mathrm{LS} 2+\mathrm{b}_{4} \mathrm{LS} 3+\mathrm{b}_{5} \mathrm{LS} 4+\square_{\mathrm{i}}$

where,

GPA: Cumulative grade point average

TECHSCORE: Composite score from the technology survey

Gender: Gender dummy variable $(1=$ male, $0=$ female $)$

LS2, LS3 and LS4: Learning style dummy variables for divergers, convergers and assimilators, respectively.

t-stats are in parenthesis. (*Significant at $10 \%$ level. **Significant at 5\% level. ***Significant at $1 \%$ level. )

2. Following Loo (2002), hard majors include Accounting, Actuarial Science, Economics, Finance, Information Systems and related joint majors such as Accounting/Finance, Actuarial Science/Finance, Accounting/Actuarial Science and Accounting/Information Systems. Soft majors include General Business, International Business, Management and Marketing.

3. Students in both hard and soft majors are excluded. 
NOTES 